\title{
Basophil Recruitment to Skin Lesions of Patients with Systemic Lupus Erythematosus Mediated by CCR1 and CCR2
}

\author{
Qingjun Pan Yongmin Feng Yanxia Peng Hongjiu Zhou Zhenzhen Deng \\ Lu Li Huanqin Han Jieping Lin Lei Shi Shujun Wang Ning An Chen Yang \\ Hua-feng Liu
}

Key Laboratory of Prevention and Management of Chronic Kidney Disease of Zhanjiang City, Institute of Nephrology, Affiliated Hospital of Guangdong Medical University, Zhanjiang, Guangdong, China

\section{Key Words}

Systemic lupus erythematosus • Basophil • Skin lesions $•$ CCR1 • CCR2

\begin{abstract}
Background/Aims: Basophils have been reported to infiltrate skin lesions in various skin diseases, but not in systemic lupus erythematosus (SLE). This study investigated basophil infiltration in SLE and its mechanism. Methods: Twenty newly diagnosed SLE patients and twenty healthy controls were enrolled. Nine SLE patients underwent skin biopsies. Flow cytometric analysis the phenotype of peripheral basophils and their migration rate toward RANTES and MCP-1 were analyzed with the transwell culture system, also the expression of these two chemokines in skin tissue were analyzed with immunohistochemistry. Results: Increased activation and decreased numbers of peripheral basophils were observed in SLE patients compared with controls. Basophil migration into skin lesions of SLE patients were observed, but not in normal skin tissue. This migration was related to the upregulation of chemokine receptors CCR1 and CCR2 on basophils. In vitro studies showed that migration rate toward RANTES and MCP-1 increased significantly in basophils from SLE patients compared with those from controls. Consistently, high levels of RANTES and MCP-1 expression were observed in skin lesions from SLE patients but not in normal skin tissue. Conclusion: Basophil recruitment to skin lesions of SLE patients mediated by CCR1 and CCR2, which may contribute to tissue damage in SLE.
\end{abstract}




\section{Introduction}

Basophils are the least abundant granulocyte, representing $1 \%$ of circulating leukocytes. However, recent studies have highlighted its emerging role in health and disease [1]. Our increasing understanding of the function of basophils in immunology is based on newly developed functional analysis tools, including basophil-depleting antibodies (e.g., monoclonal antibodies specific for the high-affinity IgE receptor [FceRI] and CD200 Receptor-like 3 [CD200R3]) and genetically engineered mice that are only deficient in basophils [2-4]. These advances have fueled basophil research and defined previously unrecognized basophil functions.

Basophils have been reported to infiltrate into skin lesions in various inflammatory and allergic skin diseases, such as atopic dermatitis, urticaria, bullous pemphigoid, drug eruptions, insect bites, scabies, and dermatomyositis [5]. Chemokines and their receptors help regulate this inflammatory site infiltration. Human basophils express the chemokine receptors (CCR)1, CCR2, CCR3, and CCR5 to mediate their infiltration into inflammatory sites $[6,7]$. However, further investigations are needed to determine which chemokine receptors are involved in mediating basophil infiltration of skin lesions and what specific circumstances elicit this infiltration.

Systemic lupus erythematosus (SLE) is a chronic inflammatory disease involving multiple organs, including skin, brain, lungs, and kidneys [8,9]. Skin lesions are a common presentation in patients with SLE. As many as $70 \%$ of people with lupus have some skin symptoms, and approximately $25 \%$ of patients have cutaneous manifestations as a presenting sign $[10,11]$. Skin involvement is second only to joint manifestations as the predominant manifestation of SLE, both at onset and later stages of the disease [12, 13]. Cutaneous manifestations are correlated with disease activity in SLE, which gives them diagnostic value [14]. As was known, several types of immune cells [15-17], including basophils [18] have been reported to exacerbate SLE by amplifying production of autoantibodies and inflammatory cytokines. However, we do not know if basophils infiltrate skin lesions in SLE, and if they do, what are the mechanisms of this infiltration.

This study aimed to investigate basophil infiltration into SLE skin lesions and the infiltration mechanism, both in patients with SLE and in vitro, which should provide novel insights into the pathogenesis of skin lesions in SLE.

\section{Materials and Methods}

\section{Patients}

Twenty newly diagnosed treatment-naïve patients with SLE (SLE patients) met the diagnostic criteria for SLE, as outlined by the American College of Rheumatology (Table 1) [19]. SLE patients were enrolled in this study from August 2014 to August 2015 at the Department of Nephrology, the Affiliated Hospital of Guangdong Medical University. Twenty healthy control subjects (Table 1) with no age, sex, or race differences were also enrolled. All subjects provided peripheral blood samples. Nine of the SLE patients with cutaneous lesions underwent skin biopsies to detect tissue basophils (Table 2). Normal skin tissue from cases of trauma or surgery were used as compared controls. The disease activity of the SLE patients was evaluated using the SLE disease activity index [20]. All participants provided written informed consent. The Ethics Committee of the Affiliated Hospital of Guangdong Medical University approved this study.

Table 1. Demographic characteristics of SLE patients and healthy controls

\begin{tabular}{lcc}
\hline Items & $\begin{array}{c}\text { SLE patients } \\
(\mathrm{n}=20)\end{array}$ & Healthy controls $(\mathrm{n}=20)$ \\
\hline Age (Mean, SD) & $26.1 \pm 8.7$ & $24.9 \pm 5.3$ \\
Gender (F/M, no.(\%) & $16(80 \%) / 4(20 \%)$ & $15(75 \%) / 5(25 \%)$ \\
Anti-dsDNA IgG positive: no. (\%) & $14(70 \%)$ & \\
SLEDAI score & \\
Mean, SD & $14.6 \pm 3.8$ & \\
Median (Minimum, Maximum) & $16(11,23)$ & \\
\end{tabular}




\section{Cellular Physiology Cell Physiol Biochem 2017;43:832-839 \begin{tabular}{ll|l} 
DOI: 10.1159/000481609 & O 2017 The Author(s). Published by S. Karger AG, Basel \\
www.karger.com/cpb
\end{tabular}}

Pan et al.: Basophil Recruitment to Skin Lesions of SLE Patients

Table 2. Demographic characteristics of patients with active cutaneous lupus lesions

\begin{tabular}{lcccccc}
\hline No. & Gender & Age & $\begin{array}{c}\text { SLEDA } \\
\text { score }\end{array}$ & $\begin{array}{c}\text { Anti-dsDNA } \\
\text { IgG }\end{array}$ & Organ involvement & Proteinuria \\
\hline 1 & F & 31 & 17 & - & Nephrology, Skin, Joints & - \\
2 & F & 33 & 13 & + & Nephrology, Skin, Joints, Hematologic & System \\
3 & F & 59 & 15 & + & Skin & + \\
4 & M & 22 & 14 & - & Skin, Joints & - \\
5 & F & 40 & 16 & - & Skin & - \\
7 & F & 62 & 16 & - & Skin, Joints \\
8 & M & 18 & 11 & + & Skin, Joints \\
9 & F & 22 & 18 & 15 & + & Skin \\
\hline
\end{tabular}

Flow cytometric analysis

Human peripheral basophils were gated on CD203c-PE and CD123-PE-Cy7 (Biolegend, San Diego, CA, USA) double-positive cells after extracellular staining. Followed, the expression levels of CD203c-PE, CCR1Alexflux-647, CCR2-Percp-Cy5.5, CCR3-APC/Cy7 and CCR5-Alexflux-488 (Biolegend, San Diego, CA, USA) in peripheral basophils were quantified and expressed as relative fluorescence units, which is defined as the mean fluorescence intensity normalized to controls.

A FACScanto ${ }^{\mathrm{TM}}$ II flow cytometer (Becton Dickinson, San Jose, CA, USA) and the Lysys II software (Becton Dickinson, San Jose, CA, USA) were used to acquire and analyze the data, respectively.

Tissue analysis

Basophils were detected in biopsied skin specimens using the basophil-specificantibody2D7 (Biolegend, San Diego, CA, USA) [21, 22]. Expression of Regulated on Activation, Normal T Cell Expressed and Secreted (RANTES) and monocyte chemotactic protein 1 (MCP-1) was determined using immunohistochemistry with anti-MCP1 and anti-RANTES antibodies (Abcam, Cambridge, MA, USA).

\section{Migration assays}

A transwell system (Biolegend, San Diego, CA, USA) was using to detect basophil migration toward RANTES and MCP-1. Briefly, peripheral blood mononuclear cells were isolated from SLE patients and healthy controls using a density gradient procedure (Ficoll-Paque PLUS, GE Healthcare Life Sciences) and resuspended at a cell density of $5 \times 10^{6}$ cells $/ \mathrm{ml}$ in Dulbecco's Modified Eagle Medium (DMEM) (SigmaAldrich, St. Louis, Missouri, USA) containing 10\% FBS (Gibco-Brl, Grand Island, NY, USA). Cell suspensions $(100 \mu \mathrm{l})$ were pipetted into the upper wells. RANTES $(100 \mathrm{ng} / \mathrm{ml})$ or MCP-1 (100 ng/ml) in $600 \mu \mathrm{l}$ of DMEM were added to the lower chambers. DMEM alone served as the spontaneous-migration control, and cells pipetted into the lower well served as a positive control. Cells were incubated for $2 \mathrm{~h}$ at $37^{\circ} \mathrm{C}$ under $5 \% \mathrm{CO}_{2}$. Following the incubation period, migrated cells were harvested and stained for flow cytometric analysis as described in Materials and Methods 2.2. RANTES- and MCP-1-induced basophil migration levels were calculated by subtracting the percentage of spontaneously migrating basophils.

\section{Statistical Analysis}

All statistical analyses were performed using SPSS 16.0. Two-group comparisons were performed using an independent one-sample t-test. A P-value of $<0.05$ was considered statistically significant.

\section{Results}

SLE patients had increased activity and decreased numbers of peripheral basophils

The representative data of FACS for basophil frequency, CD203c expression were shown (Fig. 1a). Compared with healthy controls, the basophils in peripheral blood of SLE patients were activated and had increased expression of the activation marker CD203c (Fig. 1b). However, the number (Fig. 1c) and percentage (Fig. 1d) of peripheral basophils in SLE 
patients were significantly decreased compared with those of healthy controls. These results indicate that peripheral basophil activation could play a role in SLE.

\section{Basophils infiltrate skin lesions of SLE patients}

To further explore the decreased numbers of peripheral basophils in SLE patients, we examined the recruitment of basophils to skin lesions in SLE patients [5]. In eight of nine SLE patients with cutaneous lesions receiving skin biopsy, basophils were located in the superficial dermis and perivascular regions of inflammatory sites (Fig. 2b and c). Basophils were not present in normal skin tissue (Fig. 2a).

\section{Basophils from SLE patients have higher expression of CCR1 and CCR2}

Chemokines and their receptors are involved in the regulation of infiltration into cellular inflammatory sites. Human basophils are known to mediate infiltration by expressing the chemokine receptors CCR1, CCR2, CCR3, and CCR5 [6, 7]. Therefore, we investigated the mechanisms mediating basophil infiltration in skin lesions of SLE patients by evaluating the levels of these CCRs in peripheral basophils. Expression of CCR1 and CCR2 on basophils was significantly higher in SLE patients than healthy controls (Fig. 3). There was no difference in the expression of CCR3 and CCR5 between SLE patients and healthy controls (data not shown). These findings indicate that CCR1 and CCR2 mediate basophil recruitment to skin lesions in SLE patients.

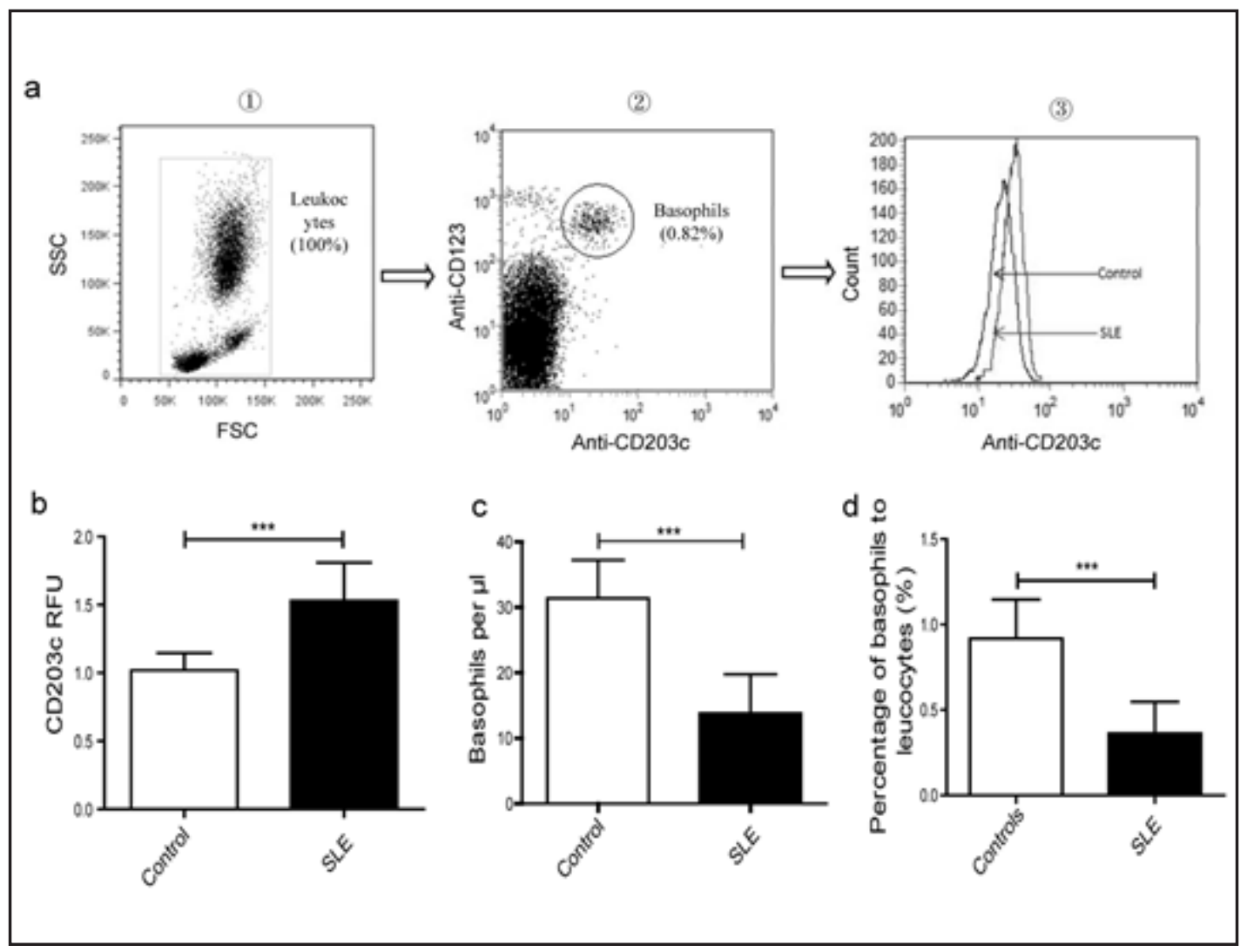

Fig. 1. Activation and numbers of peripheral basophils in SLE patients. The representative data of FACS for peripheral basophil frequency (1) dot-plot of leukocytes; (2) dot-plot of percentage of peripheral basophils in leukocytes) and CD203c expression (3) in SLE patient and healthy control were shown (Fig. 1a). Peripheral basophils in SLE patients (black bar, $n=20$ ) and healthy controls (white bar, $n=20$ ) were detected using flow cytometry and activation was determined based on CD203c expression (a). The numbers of basophils were determined based on (b) basophils per $\mu$ l and (c) percentage of basophils to leucocytes. Data are presented as means \pm S.D. ${ }^{* * *} \mathrm{P}<0.001$. 


\section{Cellular Physiology and Biochemistry Published \begin{tabular}{l|l} 
DOI: 10.1159/000481609 & (c) 2017 The Author(s). Published by S. Karger AG, Basel \\
www.karger.com/cpb
\end{tabular}

Fig. 2. Infiltration of basophils in skin lesions of SLE patients. Representative images of immunohistochemistry for basophils in skin biopsies of (A) healthy controls $(n=9)$ and $(b, c)$ SLE patients $(\mathrm{n}=8)$. Basophils were stained using 2D7 antibody. Black rectangles indicate the areas of the field shown in higher magnification at the corners of the pan-

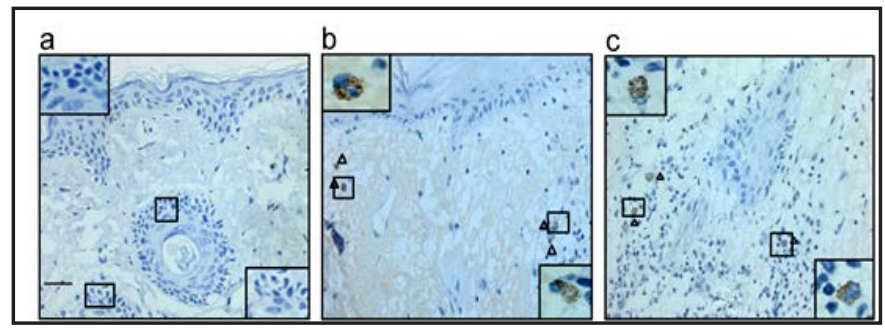
el. (Scale bars, $25 \mu \mathrm{m}$ ).

Fig. 3. Expression of CCR 1 and CCR2 on peripheral basophils in SLE patients. The expression of (a) CCR1 and (b) CCR2 on peripheral basophils obtained from healthy controls (white bars, $\mathrm{n}=20$ ) and SLE patients (black bars, $n=20$ ) was detected using flow cytometry. Data are presented as means \pm S.D. ${ }^{* * *} \mathrm{P}<0.001$.

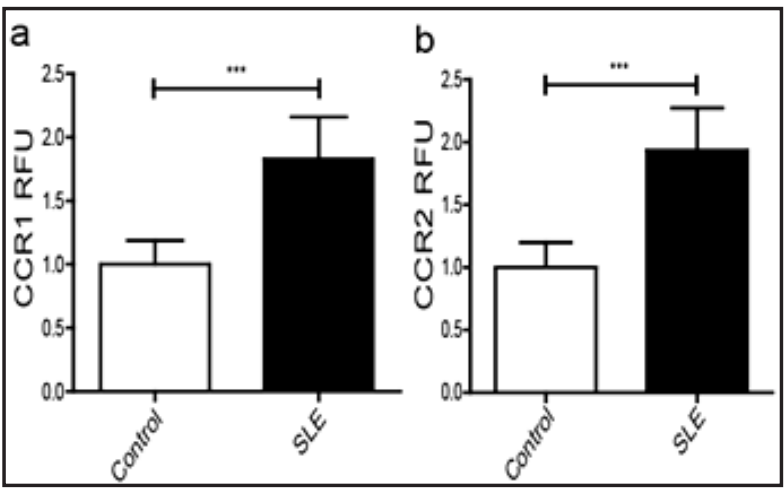

Fig. 4. Migration of basophils. A transwell invasion system was used to determine the migration rate of peripheral basophils from healthy controls (white bars, $n=6$ ) and SLE patients (black bars, $\mathrm{n}=6$ ) toward (a) RANTES and (b) MCP-1. Data are presented as means \pm S.D of three independent experiments. ${ }^{* *} \mathrm{P}<0.01$; ${ }^{* * *} \mathrm{P}<0.001$.

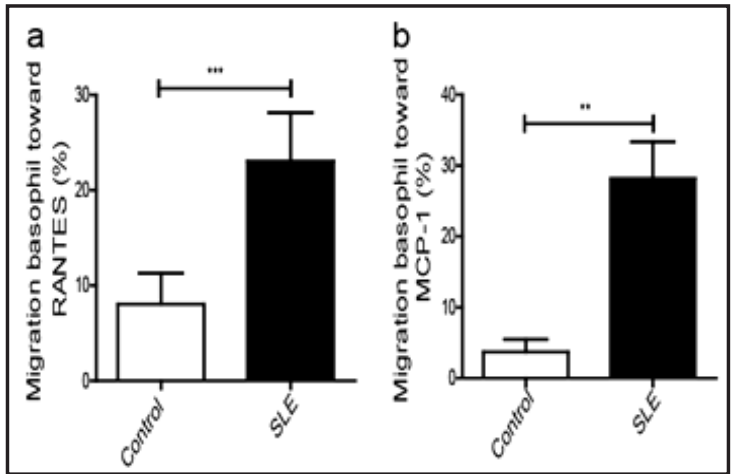

Basophils of SLE patients have a higher migration rate toward RANTES and MCP-1

RANTES and MCP-1 are the ligands for CCR1 and CCR2, respectively. Thus, the migratory capacities of basophils toward RANTES and MCP-1 were analyzed [23]. Peripheral basophils from SLE patients had a higher migration rate than those from healthy controls (Fig. 4).

Skin lesions from SLE patients had higher expression of RANTES and MCP-1

The observation that basophils of SLE patients have a higher migration rate toward RANTES and MCP-1 in vitro prompted us to investigate whether these skin lesions express RANTES and MCP-1. Consistent with the previous results, high MCP-1 and RANTES expression levels were observed in skin lesions from SLE patients but not those from healthy controls (Fig. 5).

\section{Discussion}

Basophils play nonredundant roles in acquired immunity regulation, protective immunity to pathogens, and immunological disorders through the release of cytokines and lipid mediators. They also function as antigen-presenting cells [24-26]. However, their 


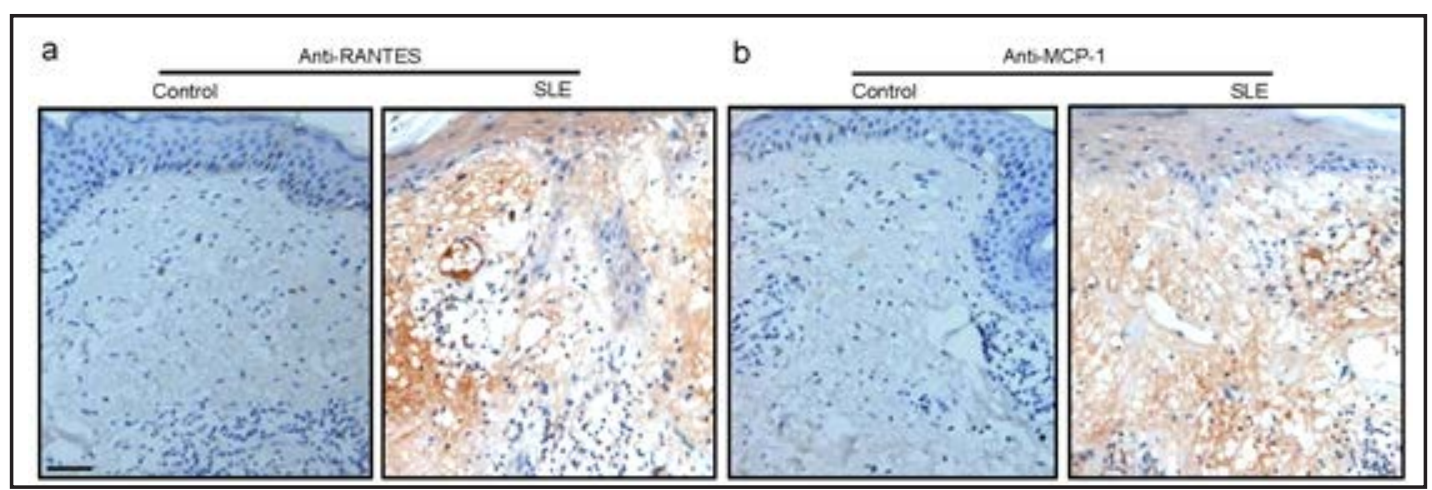

Fig. 5. Expression of RANTES and MCP-1 in skin lesions of SLE patients. Immunohistochemistry detection of (A) RANTES and (B) MCP-1 expression was performed in skin biopsies of healthy controls (n=9) and SLE patients (n=9). (Scale bars, $25 \mu \mathrm{m})$.

function in autoimmunity remains poorly understood [18, 27]. The role of basophils in mice has been investigated extensively, both in vivo and in vitro [28-31], but not in humans. Thus, there is limited first-hand evidence of what human basophils actually do in in vivo immune responses [32]. In this study, we used human basophils and clinical data to demonstrate that CCR1 and CCR2 mediate basophil recruitment in skin lesions of SLE patients.

Basophils need to be activated to fulfill their biological functions [33, 34]. Here, we showed that peripheral basophils were activated and the number of peripheral basophils decreased in SLE patients. We observed basophil infiltration into skin lesions obtained from SLE patients. This process potentially could be mediated by increased expression of the chemokine receptors CCR1 and CCR2 on the surface of basophils. Further, transwell migration assays of peripheral basophils from SLE patients showed increased migration toward the chemokine ligands RANTES and MCP-1 compared with basophils from healthy subjects. Consistent with this observation, we detected high expression of RANTES and MCP-1 in tissue from skin lesions of SLE patients. Another aspect, migration to lymph nodes mediated by CD62L also contributing to the decrease of peripheral basophils in patients with SLE [18].

Infiltration of basophils in the skin of inflammatory skin diseases has been addressed previously [5]. In this study, eight of nine SLE patients with biopsied skin lesions had basophils in the superficial dermis and perivascular regions of inflammation sites, but no basophils were detected in healthy controls. A previous study by Ito et al. did not find basophils in the skin lesions of the three SLE patients they biopsied [5]. This observation may be due to small sample sizes or because they detected basophils using a different basophil-specific antibody. However, in our study, there was one SLE patient without basophils in their skin lesions. Future studies will need larger samples and more participants to determine why infiltration differs and why some few lesions lack basophils in SLE patients. Furthermore, there are classes of molecules that are involved in the function of immune cells [35-37], and the regulation of leukocyte migration and activation by chemokines could contribute to the induction of acute and chronic inflammatory reactions. The CCR ligands RANTES and MCP-1 have been shown to play an important role in lung leukocyte infiltration and the recruitment of eosinophils in asthma pathogenesis [23]. Moreover, injection of RANTES and MCP-1 in rat skin causes mast cell, eosinophil, and macrophage recruitment [23]. Our results showed that the migration rate of basophils toward RANTES and MCP-1 increased in SLE patients, which was consistent with the higher expression of MCP-1 and RANTES at skin lesions of SLE patients.

In summary, this study demonstrates that CCR1 and CCR2 could mediate basophil migration and recruitment to skin lesions of SLE patients, which could contribute to tissue damage in SLE. These findings provide novel insights into the pathogenesis of skin lesions in SLE patients and could lead to the development of new therapeutic strategies for treating SLE. 


\section{Cellular Physiology Cell Physiol Biochem 2017;43:832-839 \begin{tabular}{l|l|l} 
and Biochemistry Published online: September 28, 2017 & $\begin{array}{l}\text { (c) } 2017 \text { The Author(s). Published by S. Karger AG, Basel } \\
\text { www.karger.com/cpb }\end{array}$
\end{tabular}}

\section{Acknowledgements}

National Natural Science Foundation of China (81202346) and Guangdong Natural Science Foundation, China (S2012040006216).

\section{Disclosure Statement}

None.

\section{References}

1 Vasquez A: Reply to “role of Western diet in inflammatory autoimmune diseases" by Manzel et al. In current allergy and asthma reports (volume 14, issue 1, January 2014). Curr Allergy Asthma Rep 2014;14:454.

2 Sokol CL, Barton GM, Farr AG, Medzhitov R: A mechanism for the initiation of allergen-induced T helper type 2 responses. Nat Immunol 2008;9:310-318.

-3 Obata K, Mukai K, Tsujimura Y, Ishiwata K, Kawano Y, Minegishi Y, Watanabe N, Karasuyama H: Basophils are essential initiators of a novel type of chronic allergic inflammation. Blood 2007;110:913-920.

4 Matsuoka K, Shitara H, Taya C, Kohno K, Kikkawa Y, Yonekawa H: Novel basophil- or eosinophil-depleted mouse models for functional analyses of allergic inflammation. PLoS One 2013;8:e60958.

5 Ito Y, Satoh T, Takayama K, Miyagishi C, Walls AF, Yokozeki H: Basophil recruitment and activation in inflammatory skin diseases. Allergy 2011;66:1107-1113.

-6 Marone G, Triggiani M, de Paulis A: Mast cells and basophils: friends as well as foes in bronchial asthma? Trends Immunol 2005;26:25-31.

-7 Iikura M, Miyamasu M, Yamaguchi M, Kawasaki H, Matsushima K, Kitaura M, Morita Y, Yoshie 0, Yamamoto K, Hirai K: Chemokine receptors in human basophils: inducible expression of functional CXCR4. J Leukoc Biol 2001;70:113-120.

-8 Frieri M: Mechanisms of disease for the clinician: systemic lupus erythematosus. Ann Allergy Asthma Immunol 2013;110:228-232.

-9 Apostolidis SA, Lieberman LA, Kis-Toth K, Crispín JC, Tsokos GC: The dysregulation of cytokine networks in systemic lupus erythematosus. J Interferon Cytokine Res 2011;31:769-779.

10 Yell JA, Mbuagbaw J, Burge SM: Cutaneous manifestations of systemic lupus erythematosus. Br J Dermatol 1996;135:355-362.

11 Jabłonska S, Błaszczyk-Kostanecka M, Chorzelski T, Jarzabek-Chorzelska M: The red face: lupus erythematosus. Clin Dermatol 1993;11:253-260.

12 Vitali C, Bencivelli W, Isenberg DA, Smolen JS, Snaith ML, Sciuto M, d’Ascanio A, Bombardieri S: Disease activity in systemic lupus erythematosus: report of the Consensus Study Group of the European Workshop for Rheumatology Research. I. A descriptive analysis of 704 European lupus patients. European Consensus Study Group for Disease Activity in SLE. Clin Exp Rheumatol 1992;10:527-539.

-13 Drake LA, Dinehart SM, Farmer ER, Goltz RW, Graham GF, Hordinsky MK, Lewis CW, Pariser DM, Skouge JW, Webster SB, Whitaker DC, Butler B, Lowery BJ, Sontheimer RD, Callen JP, Camisa C, Provost TT, Tuffanelli DL: Guidelines of care for cutaneous lupus erythematosus. American Academy of Dermatology. J Am Acad Dermatol 1996;34:830-836.

14 Zecević RD, Vojvodić D, Ristić B, Pavlović MD, Stefanović D, Karadaglić D: Skin lesions--an indicator of disease activity in systemic lupus erythematosus? Lupus 2001;10:364-367.

15 Jiang P, Bian M, Ma W, Liu C, Yang P, Zhu B, Xu Y, Zheng M, Qiao J, Shuai Z, Zhou X, Huang D: Eryptosis as an underlying mechanism in systemic lupus erythematosus-related anemia. Cell Physiol Biochem 2016;40:1391-1400.

16 Li F, Yang Y, Zhu X, Huang L, Xu J: Macrophage polarization modulates development of systemic lupus erythematosus. Cell Physiol Biochem 2015;37:1279-1288.

17 Yu M, Song Y, Zhu MX, Liang W, Long Q, Ding PW, Xie Y, Liao YH, Yuan J: B10 cells ameliorate the progression of lupus nephritis by attenuating glomerular endothelial cell injury. Cell Physiol Biochem 2015;36:21612169. 


\section{Cellular Physiology Cell Physiol Biochem 2017;43:832-839 and Biochemistry DOI: 10.1159/000481609 \begin{tabular}{l|l} 
O 2017 The Author(s). Published by S. Karger AG, Basel \\
wwww.karger.com/cpb
\end{tabular}

18 Pan Q Gong L, Xiao H, Feng Y, Li L, Deng Z, Ye L, Zheng J, Dickerson CA, Ye L, An N, Yang C, Liu HF: Basophil activation-dependent autoantibody and IL-17 production exacerbate systemic lupus erythematosus. Front Immunol 2017, 8:348.

19 Hochberg MC: Updating the American College of Rheumatology revised criteria for the classification of systemic lupus erythematosus. Arthritis Rheum 1997;40:1725.

20 Gladman DD, Ibañez D, Urowitz MB: Urowitz, Systemic lupus erythematosus disease activity index 2000 J Rheumatol 2002;29:288-291.

-21 Irani AM, Huang C, Xia HZ, Kepley C, Nafie A, Fouda ED, Craig S, Zweiman B, Schwartz LB: Immunohistochemical detection of human basophils in late-phase skin reactions. J Allergy Clin Immunol 1998;101:354-362.

-22 Kepley CL, Craig SS, Schwartz LB: Identification and partial characterization of a unique marker for human basophils. J Immunol 1995;154:6548-6555.

23 Conti P, DiGioacchino M: MCP-1 and RANTES are mediators of acute and chronic inflammation. Allergy Asthma Proc 2001;22:133-137.

24 Chirumbolo S: State-of-the-art review about basophil research in immunology and allergy: is the time right to treat these cells with the respect they deserve? Blood Transfus 2012;10:148-164.

25 Karasuyama H, Mukai K, Obata K, Tsujimura Y, Wada T: Nonredundant roles of basophils in immunity. Annu Rev Immunol 2011;29:45-69.

-26 Wada T, Ishiwata K, Koseki H, Ishikura T, Ugajin T, Ohnuma N, Obata K, Ishikawa R, Yoshikawa S, Mukai K, Kawano Y, Minegishi Y, Yokozeki H, Watanabe N, Karasuyama H: Selective ablation of basophils in mice reveals their nonredundant role in acquired immunity against ticks. J Clin Invest 2010;120:2867-2875.

27 Pellefigues C, Charles N: The deleterious role of basophils in systemic lupus erythematosus. Curr Opin Immunol 2013;25:704-711.

-28 Denzel A, Maus UA, Rodriguez Gomez M, Moll C, Niedermeier M, Winter C, Maus R, Hollingshead S, Briles DE, Kunz-Schughart LA, Talke Y, Mack M: Basophils enhance immunological memory responses. Nat Immunol 2008; 9:733-742.

29 Perrigoue JG, Saenz SA, Siracusa MC, Allenspach EJ, Taylor BC, Giacomin PR, Nair MG, Du Y, Zaph C, van Rooijen N, Comeau MR, Pearce EJ, Laufer TM, Artis D: MHC class II-dependent basophil-CD4+ T cell interactions promote T(H)2 cytokine-dependent immunity. Nat Immunol 2009;10:697-705.

30 Yoshimoto T1, Yasuda K, Tanaka H, Nakahira M, Imai Y, Fujimori Y, Nakanishi K: Basophils contribute to $\mathrm{T}(\mathrm{H}) 2-\mathrm{IgE}$ responses in vivo via IL-4 production and presentation of peptide-MHC class II complexes to CD4+ T cells. Nat Immunol 2009;10:706-712.

-31 Sokol CL, Chu NQ, Yu S, Nish SA, Laufer TM, Medzhitov R: Basophils function as antigen-presenting cells for an allergen-induced T helper type 2 response. Nat Immunol 2009;10:713-720.

32 Min B: Basophils: what they 'can do' versus what they 'actually do',' Nat Immunol 2008;9:1333-1339.

-33 Karasuyama H, Mukai K, Tsujimura Y, Obata K: Newly discovered roles for basophils: a neglected minority gains new respect. Nat Rev Immunol 2009;9:9-13.

-34 MacGlashan D Jr: IgE receptor and signal transduction in mast cells and basophils. Curr Opin Immunol 2008;20:717-723.

-35 He XJ, Ding Y, Xiang W, Dang XQ: Roles of 1, 25(OH)2D3 and vitamin D receptor in the pathogenesis of rheumatoid arthritis and systemic lupus erythematosus by regulating the activation of CD4+ T cells and the PKC /ERK signaling pathway. Cell Physiol Biochem 2016;40:743-756.

-36 Liu D, Zhang N, Zhang X, Qin M, Dong Y, Jin L: MiR-410 down-regulates the expression of interleukin-10 by targeting STAT3 in the pathogenesis of systemic lupus erythematosus. Cell Physiol Biochem 2016;39:303315.

-37 Li F, Zhu X, Yang Y, Huang L, Xu J: TIPE2 alleviates systemic lupus erythematosus through regulating macrophage polarization. Cell Physiol Biochem 2016;38:330-339. 